\title{
Talented Employees in the Field of Brownfields
}

\author{
Marcela Davidová1,a and Petra Horváthová2 \\ ${ }^{1}$ VŠB-Technical University of Ostrava, Faculty of Mining and Geology, Institute of Environmental Engineering, 17. listopadu 15, 70833 \\ Ostrava-Poruba, Czech Republic \\ ${ }^{2}$ VŠB-Technical University of Ostrava, Faculty of Economics, Department of Management, Sokolská tř. 33, 70121 Ostrava 1, Czech \\ Republic 322-442
}

\begin{abstract}
The article is aimed at bringing information on one of the important terms for successful redevelopment, recovery and operation of brownfields - efficient people, employees. Not only brownfields, but generally all organizations that want to be competitive and successful, want to outperform their present rivals and considerably increase their added value have to pay attention to talent management. The article is concerned, on the basis of available theoretical information and the existing practical experience, at describing three particular processes of talents management (their identification, development and retention) which are necessary for the successful use of talent. The purpose of the article is providing recommendation how to help operators of brownfields identify and retain highly talented employees, build on their strong points, reward their success, provide them with a chance to make progress, and increase their overall efficiency.
\end{abstract}

\section{Introduction}

Surely we can agree with the statement that human resources are becoming, in the present brownfields environment and in the conditions of competition and globalization increasing pressures, for organizations a more and more pivotal factor. The main competitive advantage is not financial means, modern and efficient technology and technique or quality strategy but people, efficient employees. Organizations-investors that want to survive and expand, to outperform their present rivals and considerably increase their added value in such environment have to attract, cultivate and maintain talented employees - they have to pay attention to talent management. A number of talented individuals in the population are quite limited [1].

Precondition for effective talent management in an organization is its introduction and its support by the organization's management, the interconnection of the talent management strategy (which is the basis for talent management working with the organization's business strategy) and also the allocation of a sufficient quantity of resources (and not just financial) for its implementation and use in the organization.

The aim of a talent management strategy is to ensure a pool of highly talented, skilled, committed, and loyal individuals able to contribute to the achievement of present as well as future requirements of the organization.

The objective of the article is providing recommendations to brownfields' operators how to manage talents that's mean to help them identify and retain highly talented employees, build on their strong points, reward their success, provide them with a chance to make progress, and increase their overall efficiency.

\section{Talent management processes}

On the basis of available theoretical information and the existing practical experience we can describe three particular processes of talents management identification, development and retention of talents. Each of these processes includes quite a number of activities which will be described in detail in the following sections.

\subsection{Identification of talents}

The first step the organization has to take is to identify key roles. These are such positions in the organization which, if they are not filled, may seriously disturb working of the organization. The organization has to assess whether there are available employees with key competencies who will be needed in the future in dependency with business strategy. As long as it has not sufficient existing resources then it has to find these talents. It may identify them among its present employees, from the internal resources or obtain them from the external resources.

\footnotetext{
a Corresponding author: marcela.davidova@vsb.cz
} 
The whole process of talent identification consists of three basic steps: first - the identification of key competences and creation of a rating scale to specify talents' contributions to the organization, second performance appraisal and a potential prediction, and the creation of measuring scales for their measurement, third - the creation of a talent-pool.

An important step that the organization has to take in talent management is to identify key competences of the organization, which are competences crucial for the success of every employee and thus of the whole organization.

After that key competences are determined and defined, performance appraisal and a prediction of individuals' potential follow. Performance appraisal is the measurement of actually achieved results within those areas for which the specified individual is responsible, and/or competencies understood as critical for the success of performed work as well as of the entire organization. A measuring scale most often used in organizations is as follows: considerably exceeds expectations (5), exceeds expectations (4), comes up to organization's expectations (3), below expectations (2), deep below expectations (1).

Prediction of a potential is in fact a prognosis by how many levels within the organization an employee can advance on the basis of their past/current performance appraisal, training and development, preferences in their careers, and the current and planned levels of competencies. A scale most often used by organizations is as follows: a high potential (5) $\rightarrow$ it is possible to promote by two levels or even more, a higher potential (4) $\rightarrow$ it is possible to promote by maximum two levels, an average potential (3) $\rightarrow$ it is possible to promote by one level, a limited potential (2) $\rightarrow$ ready for a lateral redeployment, no potential $(1) \rightarrow$ it is not possible to promote at the moment [1].

There are a number of methods the organization can use for performance appraisal and a forecast of employees' potential both from the internal and external sources. Talents from own sources are usually sought for through a working system of regular appraisal within which a number of methods are utilized. To the most used methods belong the method of assessment according to set objectives (MBO Management by Objectives), assessment centre, the analysis of critical events, and a $360^{\circ}$ feedback. In order to identify talents from the external sources the tests of fitness, a method of assessment centre and behavioural (competent) talks can be used.

After performance appraisal and a potential prediction, the very group of talented employees is identified - a talent-pool is being shaped. Individuals meeting in advance determined criteria (e.g. performance has to be evaluated as such which exceeds expectations (5) or considerably exceeds expectations (4), or meets expectations, and a potential has to be predicted as high (5), or higher (4), or average (3) and it can be jointly indicated as talents or this group of talented individuals can be furthermore divided into three groups - top talents, talents and potential talents. The decision whether only talents or top talents or talents or all three groups will be included into programs for talents depends on the organization [2].

But this is not the end of the systematic approach to talent and talent management. Further steps follow development and retention of talent.

\subsection{Developmentx of talents}

The organization should offer talented individuals the chance to develop their strengths, improve their total performance as well as their particular competences; strengthening their motivation and making their career development possible.

A special development plan should be made for talented employees in close cooperation with their managers. This plan should resemble the integral program for the specified group of talent and should be supplemented by the particular participants' individual needs.

Long-term training programs are not recommended in the current rapidly changing world. Organizations should prefer shorter but well drawn up programs that are relevant to their needs and for which there is a faster return on investment.

A development program may include a combination of various methods, activities or instruments of talent development, but always according to the specific needs of the specific organization. The methods employed are both the methods used for development at a workplace on job performance (on-the-job) and the methods used for development outside a workplace (off-the-job). Greater emphasis is laid on methods used for education at a workplace but, of course, both groups of methods are used [2].

Programs of talent development are very closely connected with carrier management; that is with career planning and succession planning. They provide talent with opportunities to grow in their current job roles and to move forward into roles of a higher level.

Career planning determines the advancement of talent within an organization based on the consideration of the organization's needs. Talented people should go through a certain sequence of experience supplemented by couching and development programs that will help them to be prepared for more demanding job positions in the future. Succession planning should ensure that an organization will have enough talent to satisfy its business needs in the future. Succession planning is about planning key roles, in particular.

By the development of talent, however, work with talent is not finished. It is necessary to achieve the situation in which talent individuals remain in the organization they do not leave it. It is necessary to strive for their retention in the organization.

\subsection{Retention of talents}

Also activities ensuring retention and stabilization of talent in the organization are inseparable part of talent 
management. The aim is to ensure that talented employees stay in the organization as its devoted members and in their work engaged people that they do not have a tendency to leave because their departures have usually extraordinary impact on organization's operation, which is irrelevant to their number.

The organization should do its best to be 'an attractive employer', to be a place where people like to work, 'an excellent workplace', and 'an excellent place for work performing'. Among factors contributing for the organization to be an attractive employer there is: - The offer of interesting and valued work.

- Providing the opportunity to learning and development and advancement in career.

- Respecting a balance between the life at work and a private life by the organization

- The offer of a flexible role to talented employee.

- The offer of quality work conditions and equipment.

- Providing a feeling of recognition and respect.

- The offer of an adequate reward.

- Promotion of organization's responsibility to the society.

Among the three factors that the most influence retention of talented employees in the organization belong, the opportunity of advancement in employees' career, the offer of interesting and satisfying work, and ensuring opportunities for training and development [1].

The above-mentioned facts create a valuable offer that sound values will be observed in the organization, employees can expect good leadership, freedom and autonomy, highly incentive work, opportunities for professional advancement in employees' career and adequate remuneration. It is necessary to ensure that talented individuals would be aware of being appreciated and that they have a considerable or even a principal value for the organization [3].

For the purpose of retention of talents the organization should address the following potential activities:

Take an interest in the systems of remuneration that are not competitive, they are not unjust and unbiased. It is necessary to realize that not only financial means are in question; talent should be offered also other forms of rewards - interesting work, relevant way of acting and the like.

Tasks and job opportunities in the organization should be created in such way so that a variety of work, the importance of tasks, autonomy, checking of own work, and feedback could be ensured. Also the opportunity of education, growth and career advancement should be ensured. Some roles can be 'made-to-measure' and thus accommodate concrete individuals' needs.

The organization should do its best in order to ensure loyalty to work not only by creating work tasks and job opportunities, but also by work organization in connection with projects the talent can identify with better than with the organization as a whole.
Building of social bonds should be encouraged in the organization.

Decisions on the choice or professional advancement should be properly made so that individuals' abilities could be duly interconnected with requirements of work which is to be performed by those people.

The organization should try, in connection with preventing talent from leaving, its employees in the period after joining-up the organization will be able to adapt themselves to their work, team, and the organization as best as possible. In the starting phases of their work for the organization they should be offered the appropriate assistance, education and training.

The organization should put into effect activities that will lead to the improvement of balance between a life at work and extra-work life. This includes for example a chance of flexible work regime or flexible ways of employment respecting extra-work needs of talent.

Unfavourable work conditions should be eliminated and excessive occupational stress should be removed or made lower.

The organization should choose, inform and train managers and heads of teams in such way that they are aware of positive contribution by which they can contribute to better retention of talent. However, they have to choose the right way of managing their teams.

There are many possibilities how to retain talent in the organization, not only those that have been mentioned above. The main idea is quite simple the organization has to pay real attention to its talent. It should talk with them about their work, motivate and reward them, help them accomplish their careers etc.

\section{Conclusions}

Successful redevelopment, recovery and operation of brownfields make higher and higher demands on organizations. For organizations/investors the main asset to manage those difficult conditions are people. Without a skilled workforce, without employees equipped by required abilities and knowledge, a number of organizations/investors will not be able not only to keep up with competition but they even may not to survive under specified conditions.

One of the possible instruments of human resources successful management is the system of talent management. For organizations a conception of talent management does not bring any special requirements from the view of human resources management as well as of particular personnel activities. It concerns only a careful application of the best principles and approaches that have proved in practice, mainly in the field of acquisition and choice, education and development, remuneration, and socio-cultural and welfare activities for employees.

Talent management can be considered as one of fundamental instruments of human resources management in the organization. But what should be the organization's attitude to the management of its talented employees? It should offer them a real 
perspective and pay attention to the strategy of their management. Not to use only formal programs of talent development and concentrate on career management and succession planning but to apply a comprehensive system of talent management that will enable those talented individuals a real development and a deeper identification with the organization. This system then helps organizations identify and retain highly talented employees, build on their strengths, reward their success, provide them with opportunities for advancement and increase their overall efficiency and thus the efficiency of the whole organization.

The article described in detail how it is possible to apply talent management in organizations and also brought individual process steps for a wider application of this comprehensive and systematic approach to work with talented individuals.

\section{Acknowledgement}

The research was supported by the European Social Fund within the project CZ.1.07/2.3.00/20.0296 and by the Student Grant Competition of the Faculty of Economics, VŠB-Technical University of Ostrava within the project SP2016/123.

\section{References}

1. L.A Berger, D.R Berger. Talent management Handbook: Creating Organizational Excellence by Identifying, Developing \& Promoting Your Best People, second ed. McGraw-Hill, New York (2010)

2. J. A. Cannon, R. McGee. Talent Management and Succession Planning, CIPD, London (2007)

3. M. Armstrong, S. Taylor. Armstrong's Hanbook of Human Resource Management Practice, thirteen ed., Kogan Page, Philadelphia (2014) 